\title{
An Optimized Cloud Model Algorithm Adapted to Comprehensive Benefit Evaluation of Water-Saving Irrigation
}

\author{
Shaobo Liu ${ }^{1,2,3}$, Feng Wu ${ }^{1,2 *}$, Songmei Zai ${ }^{1,2}$, Shilong $\mathrm{Hao}^{4,5}$, \\ Shah Jahan Leghari ${ }^{6}$, Lusheng Li ${ }^{1,2}$
}

${ }^{1}$ College of Water Conservancy, North China University of Water Resources and Electric Power, Zhengzhou, Henan Province 450046, China

${ }^{2}$ Henan Key Laboratory of Water-Saving Agriculture, Zhengzhou, Henan Province 450046, China

${ }^{3}$ The Water Conservancy Bureau of Nanyang, Nanyang, Henan Province 473000, China

${ }^{4}$ Henan Key Laboratory of Ecological Safety of the South-to-North Water Transfer Project Water SourceArea, Nanyang Normal University, Nanyang, Henan Province 473000, China

${ }^{5}$ College of Surveying and Geo-informatics, North China University of Water Resources and Electric Power, Zhengzhou, Henan Province 450046, China

${ }^{6}$ College of Land Science and Technology, China Agricultural University, Beijing 100193, China

Received: 9 September 2020

Accepted: 12 November 2020

\begin{abstract}
The comprehensive benefit evaluation of water-saving irrigation in the irrigated areas is a complex and dynamic evaluation system. According to the characteristics of randomness and fuzziness of the system, an optimized cloud model algorithm for the comprehensive benefit evaluation of water-saving irrigation in the irrigated areas was constructed, and the calculation of the weight cloud model was optimized. At the same time, taking Yahekou as the research area, an evaluation system considering the ecological, economic, and social benefits was established, and the comprehensive benefits of watersaving irrigation in this area were evaluated with the optimization algorithm. The results showed that the comprehensive benefit of water-saving irrigation in the Yahekou irrigated area was evaluated as grade II "good", selecting the Normal-Water-Level-Year as a typical year, following the life cycle of winter wheat-summer maize rotation mode as the time scale. The optimization algorithm not only ensures the accuracy of evaluation results but also takes into account the uncertainty of each index factor. It opens up a new way for the comprehensive benefit evaluation of water-saving irrigation in the
\end{abstract}

*e-mail: wufeng@ncwu.edu.cn 
research area and provides a new idea for the application and optimization of the cloud model algorithm, which has certain popularization value.

Keywords: water-saving irrigation, ecology, cloud model, comprehensive evaluation, optimized algorithm

\section{Introduction}

Depleting water resources is one of the major issues, which is listed as the biggest global potential risk in the next decade [1]. Worldwide, agricultural irrigation provides $40 \%$ of the energy supply and consumes $70 \%$ of the water [2]. An important way to deal with the water crisis in many countries is to improve the efficiency of irrigation and distribute the water saved in agricultural production to industry, people and the ecological environment [3]. In China, according to statistics (Water Resources Bulletin), irrigation water consumption in agricultural production accounts for $60-65 \%$ of the total water consumption. The Chinese government has always attached great importance to the issue of agricultural water conservation. In 1998, the third plenary session of the $15^{\text {th }}$ central committee of the communist party of China proposed that "The promotion of water-saving irrigation should be taken as a revolutionary measure". On September 18, 2019, general secretary Xi-Jinping hosted a symposium on ecological protection and quality development of the Yellow River basin in Zhengzhou. The symposium focusing on the global ecological civilization construction, further defined the "Water-saving priority, space balance, system management, two-handed force" as the idea of water conservancy. It emphasized that we should adhere to the concept that clear waters and green mountains are as good as mountains of gold and silver, give priority to ecology, pursue green development, and further strengthen ecological and environmental protection in river basins. Moreover, he combined agricultural water-saving with ecological protection, the whole basin, comprehensive management and systematic management, and put forward new requirements, new ideas and new goals for agricultural water-saving in the new era.

Around the world, while water-saving irrigation is in full swing, some scholars have carried out rational thinking and relevant research on whether water-saving irrigation can save water and whether it has negative effects [3-6].

Studies show that the blind improvement of the utilization efficiency of irrigation water in water-saving irrigation projects may not save water and may have some negative effects on the ecological environment. The main reason is that various departments take more account of their own economic interests. Meanwhile, they lack more scientific and reasonable comprehensive evaluation system and indicators. In addition, they take less account of something overall macro in the preliminary design and planning of water-saving irrigation systems.

In recent years, researchers evaluated water-saving irrigation by using analytic hierarchy process [7, 8], water footprint model $[9,10]$, BP neural network model [11], entropy weight method [12], fuzzy comprehensive evaluation method $[13,14]$ and principal component analysis method [15], etc. They achieved outstanding results. However, there is still room for improvement:

(1) Evaluation scale. The effect of small-scale water-saving irrigation in fields is different from that in large-scale such as irrigated areas or river basins, due to factors such as reuse of return water during irrigation. Therefore, the evaluation index system and evaluation method used on a large scale should not be confused with those used on a small scale. Meanwhile, the comprehensive benefit of water-saving irrigation in the irrigated areas is different in different hydrological years and time scales.

(2) The evaluation process and results are greatly influenced by human factors. On the one hand, research teams and experts in different fields have different concerns, and there are different emphases in the evaluation system of water-saving irrigation, which directly affects the construction of the evaluation system, the selection of indicators, the establishment of index weight and the scientific rationality of the evaluation results. The evaluation lacks objectivity. At present, the research focuses more on the positive benefits of water-saving irrigation and ignores the negative benefits that water-saving irrigation projects may produce.

(3) The phenomenons like focusing on the efficiency of water resources utilization, paying attention to the evaluation of the economy, and ignoring the assessment of its impact on the ecological environment are widespread. In fact, for water-saving irrigation, the most active factors and the most direct objectives are "watersaving" and "food conservation", the important purpose is the ecological benefit, and the most fundamental end-result is a social benefit. Economic and ecological benefits will eventually return to social benefit.

(4) The limitation of the evaluation scope. Most of the relevant studies at present focused on the evaluation of the benefits within a specific area such as farmland, irrigated areas and river basins, meanwhile few consider the influence of water-saving irrigation projects on the outside areas. However, the water-saving irrigation project in the region will also have a certain impact on the outside of the region in terms of ecology, economy and society. 
Analytic hierarchy process (AHP) is a multi-criteria decision-making method that quantitatively describes qualitative problems by decomposing the problems to be solved as a system. Analytic hierarchy process (AHP) is simple and easy to use, but it has some problems: judgment matrix has a great dependence on experts' subjective experience, and the fuzziness and randomness between evaluation indexes are not well expressed. Fuzzy comprehensive evaluation (FCE) is a multi-criteria decision-making method that transforms qualitative problems into quantitative problems by establishing membership functions. Fuzzy comprehensive evaluation method can solve the problem of fuzziness of the evaluation object, but it can not solve the problem of subjectivity and randomness of the evaluation process. Cloud model (CM) fully describes the inevitable uncertainties like randomness and fuzziness in the qualitative description by establishing an uncertainty transformation model between qualitative concepts and their corresponding values.

This paper aimed at correcting the shortcomings of the current comprehensive evaluation of water-saving irrigation, taking irrigated areas as the spatial scale, taking Normal-Water-Level-Year as the typical year, taking the life cycle of winter wheat-summer maize rotation mode as the time scale, optimizing the analytic hierarchy process (AHP) and fuzzy comprehensive evaluation method (FCE) respectively by using improved cloud model based on the comprehensive evaluation system of water-saving irrigation, combining with the similarity calculation method of normal cloud model considering of both shape and distance, constructs the optimized cloud model algorithm which adapts to the comprehensive benefit evaluation of water-saving irrigation. On the premise of ensuring the accuracy of the evaluation results, this algorithm gives consideration to the fuzziness and randomness of the evaluation system. It breaks new ground in watersaving irrigation evaluation, improves the cloud model algorithm, broadens the new field of cloud model application, and has certain theoretical and practical significance.

\section{Material and Methods}

\section{Description of Study Site}

The Yahekou irrigated areas is located between the Tang River and Bai River in Nanyang basin $\left(32^{\circ} 23^{\prime}-\right.$ $33^{\circ} 12^{\prime} \mathrm{N}$ and $\left.112^{\circ} 21^{\prime}-113^{\circ} 00^{\prime} \mathrm{E}\right)$, China, which was built in 1966 and began to irrigate in 1970. The total area of the Yahekou is about $2428 \mathrm{~km}^{2}$, in which 20-30 km wide from east to west, $100 \mathrm{~km}$ long from north to south. The ground elevation from the north is $160 \mathrm{~m}$ and from south is $80 \mathrm{~m}$ (yellow sea elevation). The irrigated area has a subtropical monsoon climate, with an average annual temperature of $14.9^{\circ} \mathrm{C}$, evaporation rate of $558 \mathrm{~mm}$ and precipitation of $802.7 \mathrm{~mm}$. The area is composed of Baitong and Yadong irrigated areas. The Baitong irrigated areas draw water from Dazhantou dam, which is 20 kilometers below the dam of the Yahekou reservoir, and the Yadong irrigated area draw water from Yahekou reservoir directly. The designed irrigation area of the Yahekou irrigated areas is 158733.33 ha, the effective irrigation area of the Yahekou irrigated areas is 88400 ha. Through carrying on supporting and water-saving transformation in recent years, the actual maximum irrigation area of the irrigated areas has expanded from about 66666.67 ha in 1998 to 106666.67 ha in 2018 .

\section{Construction of Index System}

The basis and key for scientifically carrying out the comprehensive benefit evaluation of watersaving irrigation in irrigated areas are the selection of indicators and the establishment of the system. we set an evaluation index system for agricultural watersaving by fully considering the ecological economics and social benefits under the scientific, systematic, operable, comprehensive and representative principles. It combined the dynamic with static and referred to the ecological service value evaluation system of the similar fields such as soil and water conservation [16, 17] and the traditional comprehensive evaluation system of water-saving irrigation [18-24]. The specific steps are as follows:

- The first step was to use frequency statistical method to conduct frequency statistics on the 190 indicators appearing in the 9 comprehensive evaluation systems mentioned above and then removed some unrepresentative and repetitive indicators, and there were about 35 indicators left.

- The second step was to use the theoretical analysis method to analyze and compare the connotation, characteristics, influence efficiency, and main problems of water-saving irrigation, and then comprehensively selected 16 important indicators.

- The third step was to use the Delphi method to adjust the 16 indicators, and determined the 14 secondary indicators in the three categories of economy, ecology, and society.

In this system, the number of the factors in the three benefits of the criterion layer is different, and the closeness of the factors of the factor layer with the three benefits of the criterion layer is not consistent. In order to ensure the objectivity and accuracy of the evaluation results, the fuzzy analytic hierarchy process was introduced into the evaluation model, and the concepts of "weight" and "degree of membership" were used to express the contribution degree of each factor to the evaluation results objectively. The comprehensive evaluation system of water saving irrigation is shown in Fig. 1. 


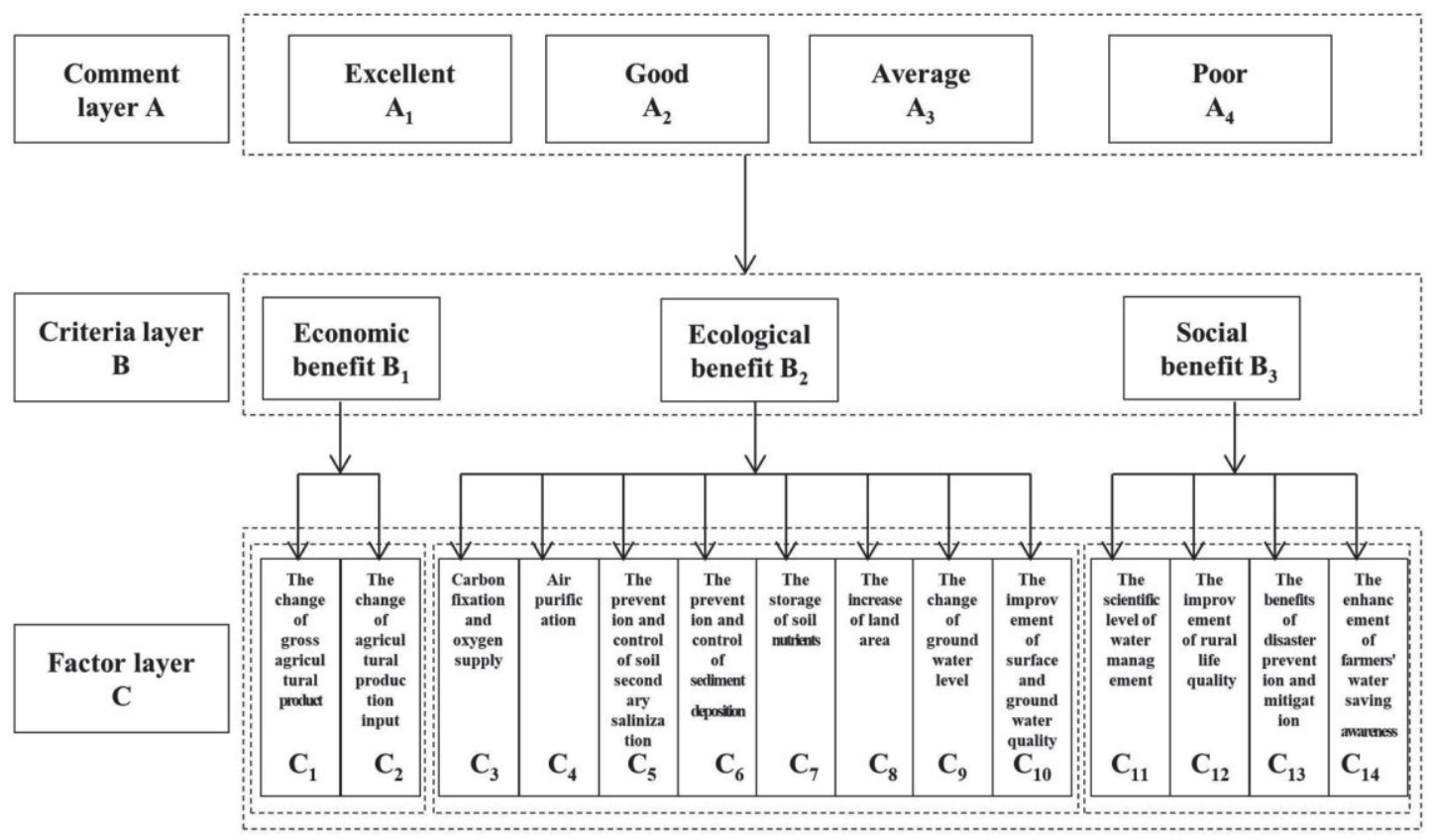

Fig. 1. Comprehensive Evaluation System of Water Saving Irrigation.

\section{Introduction of Evaluation Model}

The water-saving irrigation system in the irrigated areas is a complex nonlinear system with randomness and fuzziness in time and space under the action of multi-factor coupling. These factors, with their randomness and fuzziness determine the uncertainty of comprehensive evaluation results. This paper developed an improved cloud model algorithm for comprehensive benefit evaluation of water-saving irrigation in irrigated areas. The main steps are as follows:

- First step, the forward cloud generator, was used to calculate and generate the cloud model of the comment set.

- Second step, the cloud model was used to improve the AHP, and the relevant parameters were modified in combination with the comment set cloud model so as to determine the weight cloud model of each evaluation factor.

- Third step, the cloud model was used to improve the fuzzy comprehensive evaluation method, and the normal cloud model was used to objectively express the membership degree of the index factors to the evaluation level instead of the exact value.

- Fourth step, the similarity calculation method of the normal cloud model with both shape and distance was used to determine the final evaluation grade so as to comprehensively evaluate the agricultural water-saving irrigation benefits of the irrigated areas under uncertain conditions.

Normal cloud model is one of the most widely used in the cloud model, which has universal adaptability and wide application [25]. Therefore, all cloud models mentioned in this paper refer to normal cloud models. Every cloud model is represented by its corresponding expectation (Ex), entropy (En), and hyper entropy (He), namely C (Ex, En, He) [26].

Expectation (Ex) reflects the barycenter position of the cloud droplet and represents the central value of the comment set, factor weight, and membership. Entropy (En) represents the randomness and fuzziness of cloud droplets, reflects the possible value range of comment set, factor weight and membership, and is used to describe the width of cloud. Hyper entropy (He) is the entropy of entropy, which represents the randomness and fuzziness of entropy. It is used to describe the thickness of clouds, mainly reflects the degree of dispersion between cloud droplets, and measures the degree of deviation from the normal distribution. According to relevant research conclusions [1, 27], when $\mathrm{He}<\mathrm{En} / 3$, the cloud model is in a good state, when $\mathrm{He}>\mathrm{En} / 3$, the atomization state of the cloud model is obvious.

Cloud model realizes qualitative and quantitative conversion through forwarding and reversing cloud generators. The forward cloud generator converts qualitative concepts into quantitative values, namely, generating a certain number of accurate cloud droplets from qualitative language values (Ex, En, He). Reverse cloud generator converts quantitative values into qualitative concepts, namely, converting a certain number of exact values into corresponding qualitative language values (Ex, En, He), which is the three parameters of the cloud model.

\section{Comment Set Cloud Model}

In this paper, the comprehensive benefit evaluation set of water-saving irrigation in irrigated areas was composed of four grades: excellent, good, average, 
and poor. Each grade was represented by a normal cloud model. The four grades of evaluation cloud models jointly constituted the comprehensive benefit comment set cloud model of water-saving irrigation in irrigated areas. Referring to relevant literature [26], the calculation formula is as follows:

$$
\begin{gathered}
E x_{i}=\frac{\left(x_{i}^{u p}+x_{i}^{\text {down }}\right)}{2} \\
\exp \left[-\frac{\left(x_{i}^{u p}-x_{i}^{\text {down }}\right)^{2}}{8 E n_{i}}\right]= \\
=0.5 \quad E n_{i}=\frac{\left(x_{i}^{u p}-x_{i}^{\text {down }}\right)}{2.355} \\
H e=k
\end{gathered}
$$

In the formula, $x_{i}^{u p}$ and $x_{i}^{\text {down }}$ are the upper and lower boundaries of the four grade sets, respectively, $E x_{i}$ is the expectation corresponding to the comment set, $E n_{i}$ is the entropy corresponding to the comment set, $\mathrm{He}$ is the hyper entropy corresponding to the comment set. Refer to the definition of hyper entropy and related literature for specific details $[26,28]$, the hyper entropy in the comment set cloud model is constant, which of this paper is 0.01 .

\section{Factor Weight Cloud Model}

The determination of weight is an integral part of the fuzzy comprehensive evaluation (FCE). The analytic hierarchy process (AHP) is a more effective method to determine the weight coefficient. The traditional analytic hierarchy process (AHP) expresses the comparison of the importance of two factors in the judgment matrix, by mainly constructing the judgment matrix and using the random number of continuous quality to express the comparison of the importance of two factors in the judgment matrix, and then calculates the weight of each factor by combining with the square root method and so on. Although this method can more clearly quantify the weight of each factor, there are also shortcomings such as the strong dependence of the judgment matrix on the subjective experience of experts, and the unclear expression of randomness and ambiguity among the evaluation factors.

In recent years, the analytic hierarchy process (AHP) was improved by building weight cloud model. [29] (hereinafter referred to as "Method 1").The weight cloud model reduced the judgment matrix of the expert subjective experience dependence and better expressed the ambiguity and randomness between evaluation indicators. However, in these studies, there were also some cases where the ratio of the entropy and hyper entropy of the weight cloud model was close to 1 , and even part of the entropy was greater than expected, resulting in the ambiguity an Previous studies in related fields [27, 30] (hereinafter referred to as "Method 2") only used the judgment matrix and square root method to obtain the weight value. Only the expectation of the

\begin{tabular}{|c|c|c|c|c|}
\hline Relative importance between indicators & Cloud model & Expectation & Entropy & Hyper entropy \\
\hline $\mathrm{X}_{\mathrm{i}}$ is absolutely more important than $\mathrm{X}_{\mathrm{j}}$ & $\mathrm{D} 1\left(\mathrm{Ex}_{1}, \mathrm{En}_{1}, \mathrm{He}_{1}\right)$ & 9 & 0.33 & 0.01 \\
\hline $\mathrm{X}_{\mathrm{i}}$ is absolutely more important than $\mathrm{X}_{\mathrm{j}}$ generally & $\mathrm{D} 2\left(\mathrm{Ex}_{2}, \mathrm{En}_{2}, \mathrm{He}_{2}\right)$ & 8 & 0.33 & 0.01 \\
\hline $\mathrm{X}_{\mathrm{i}}$ is more important than $\mathrm{X}_{\mathrm{j}}$ & $\mathrm{D} 3\left(\mathrm{Ex}_{3}, \mathrm{En}_{3}, \mathrm{He}_{3}\right)$ & 7 & 0.33 & 0.01 \\
\hline $\mathrm{X}_{\mathrm{i}}$ is more important than $\mathrm{X}_{\mathrm{j}}$ generally & $\mathrm{D} 4\left(\mathrm{Ex}_{4}, \mathrm{En}_{4}, \mathrm{He}_{4}\right)$ & 6 & 0.33 & 0.01 \\
\hline $\mathrm{X}_{\mathrm{i}}$ is obviously more important than $\mathrm{X}_{\mathrm{j}}$ & $\mathrm{D} 5\left(\mathrm{Ex}_{5}, \mathrm{En}_{5}, \mathrm{He}_{5}\right)$ & 5 & 0.33 & 0.01 \\
\hline $\mathrm{X}_{\mathrm{i}}$ is obviously more important than $\mathrm{X}_{\mathrm{j}}$ generally & D6 $\left(\mathrm{Ex}_{6}, \mathrm{En}_{6}, \mathrm{He}_{6}\right)$ & 4 & 0.33 & 0.01 \\
\hline $\mathrm{X}_{\mathrm{i}}$ is slightly more important than $\mathrm{X}_{\mathrm{j}}$ & $\mathrm{D} 7\left(\mathrm{Ex}_{7}, \mathrm{En}_{7}, \mathrm{He}_{7}\right)$ & 3 & 0.33 & 0.01 \\
\hline $\mathrm{X}_{\mathrm{i}}$ is a little important than $\mathrm{Xj}$ & $\mathrm{D} 8\left(\mathrm{Ex}_{8}, \mathrm{En}_{8}, \mathrm{He}_{8}\right)$ & 2 & 0.33 & 0.01 \\
\hline $\mathrm{X}_{\mathrm{i}}$ and $\mathrm{X}_{\mathrm{j}}$ are equally important & $\mathrm{D} 9\left(\mathrm{Ex}_{0}, \mathrm{En}_{0}, \mathrm{He}_{0}\right)$ & 1 & 0 & 0 \\
\hline$X_{j}$ is a little important than $X_{i}$ & $\mathrm{D} 10\left(\mathrm{Ex}_{10}, \mathrm{En}_{10}, \mathrm{He}_{10}\right)$ & $1 / 2$ & $0.33 / 4$ & $0.01 / 4$ \\
\hline $\mathrm{X}_{\mathrm{j}}$ is slightly more important than $\mathrm{X}_{\mathrm{i}}$ & $\mathrm{D} 11\left(\mathrm{Ex}_{11}, \mathrm{En}_{11}, \mathrm{He}_{11}\right)$ & $1 / 3$ & $0.33 / 9$ & $0.01 / 9$ \\
\hline $\mathrm{X}_{\mathrm{j}}$ is obviously more important than $\mathrm{X}_{\mathrm{i}}$ generally & $\mathrm{D} 12\left(\mathrm{Ex}_{12}, \mathrm{En}_{12}, \mathrm{He}_{12}\right)$ & $1 / 4$ & $0.33 / 16$ & $0.01 / 16$ \\
\hline $\mathrm{X}_{\mathrm{j}}$ is obviously more important than $\mathrm{X}_{\mathrm{i}}$ & $\mathrm{D} 13\left(\mathrm{Ex}_{13}, \mathrm{En}_{13}, \mathrm{He}_{13}\right)$ & $1 / 5$ & $0.33 / 25$ & $0.01 / 25$ \\
\hline$X_{j}$ is more important than $X_{i}$ generally & $\mathrm{D} 14\left(\mathrm{Ex}_{14}, \mathrm{En}_{14}, \mathrm{He}_{14}\right)$ & $1 / 6$ & $0.33 / 36$ & $0.01 / 36$ \\
\hline $\mathrm{X}_{\mathrm{j}}$ is more important than $\mathrm{X}_{\mathrm{i}}$ & $\mathrm{D} 15\left(\mathrm{Ex}_{15}, \mathrm{En}_{15}, \mathrm{He}_{15}\right)$ & $1 / 7$ & $0.33 / 49$ & $0.01 / 49$ \\
\hline $\mathrm{X}_{\mathrm{j}}$ is absolutely more important than $\mathrm{X}_{\mathrm{i}}$ generally & $\mathrm{D} 16\left(\mathrm{Ex}_{16}, \mathrm{En}_{16}, \mathrm{He}_{16}\right)$ & $1 / 8$ & $0.33 / 64$ & $0.01 / 64$ \\
\hline $\mathrm{X}_{\mathrm{j}}$ is absolutely more important than $\mathrm{X}_{\mathrm{i}}$ & $\mathrm{D} 17\left(\mathrm{Ex}_{17}, \mathrm{En}_{17}, \mathrm{He}_{17}\right)$ & $1 / 9$ & $0.33 / 81$ & $0.01 / 81$ \\
\hline
\end{tabular}
weighted cloud model in "Method 1" was calculated,

Table 1. Scale criteria of the weight cloud model. 
the entropy and hyper entropy were ignored,and the cloud model was only introduced in the final fuzzy comprehensive evaluation. Although the accuracy of the evaluation results was guaranteed to a certain extent, the consideration of the uncertainty between the weighting factors was ignored.

This paper improved the previous evaluation method of the weight cloud model, which combined the relevant parameters of the comment set of the cloud model (hereinafter referred to as "Method 2"). When the entropy of the weight cloud model of a factor was greater than the comment set of the cloud model, the entropy of the weight cloud model of this factor was modified to the entropy of the comment set of the cloud model, and the hyper entropy was modified to the hyper entropy of the comment set of the cloud model, so as to achieve the purpose of improving the accuracy of the evaluation results and fully considering the randomness and ambiguity of each factor. Specific steps are as follows.

The first step was to construct the scale criterion of the cloud model of evaluation factor weight of watersaving irrigation in irrigated areas, as shown in Table 1.

The second step was to organize experts and scholars from local and related scientific research institutions to compare the importance of factors and various benefits in the factor layer with the scale criterion constructed in the first step and then to establish a judgment matrix.

The third step was to calculate the maximum eigenvalue of the judgment matrix and the corresponding eigenvector and conduct a consistency test. If the test passes, the next step is conducted. If the test fails, the feedback communication with relevant scholars is needed to adjust the established judgment matrix until the consistency test passes. The specific algorithm is as follows [27, 31]:

$$
C R=\frac{C I}{R I}=\frac{\left(\lambda_{\max }-n\right)}{(n-1) \cdot R I}
$$

$C R$ represents the consistency ratio of the judgment matrix, When $C R<1$, it means that the consistency test of the judgment matrix has passed, $\lambda_{\max }$ represents the largest characteristic root of the judgment matrix, $C I$ represents the consistency index of the judgment matrix, $R I$ represents the average random consistency factor of the judgment matrix. This factor is only related to the order of the judgment matrix, and its corresponding relationship with the order is shown in Table 2.

The fourth step was to use the square root method to calculate the relevant parameters $R_{i}^{0}\left(E x_{i}^{0}, E n_{i}^{0}, H e_{i}^{0}\right)$ of each factor weight cloud model, and the specific formula is (5)-(7).

$$
\begin{gathered}
E x_{i}^{0}=\frac{E x_{i}}{\sum E x_{i}}=\frac{\left(\prod_{j=1}^{n} E x_{i j}\right)^{\frac{1}{n}}}{\sum_{i=1}^{n}\left(\prod_{j=1}^{n} E x_{i j}\right)^{\frac{1}{n}}} \\
E n_{i}^{0}=\frac{E n_{i}}{\sum E n_{i}}=\frac{\left(\prod_{j=1}^{n} E x_{i j} \sqrt{\left.\sum_{j=1}^{n}\left(\frac{E n_{i j}}{E x_{i j}}\right)^{2}\right)^{\frac{1}{n}}}\right.}{\sum_{i=1}^{n}\left(\prod_{j=1}^{n} E x_{i j} \sqrt{\sum_{j=1}^{n}\left(\frac{E n_{i j}}{E x_{i j}}\right)^{2}}\right)^{\frac{1}{n}}} \\
H e_{i}^{0}=\frac{H e_{i}}{\sum H e_{i}}=\frac{\left(\prod_{j=1}^{n} E x_{i j} \sqrt{\left.\sum_{j=1}^{n}\left(\frac{H e_{i j}}{E x_{i j}}\right)^{2}\right)^{\frac{1}{n}}}\right.}{\sum_{i=1}^{n}\left(\prod_{j=1}^{n} E x_{i j} \sqrt{\sum_{j=1}^{n}\left(\frac{H e_{i j}}{E x_{i j}}\right)^{2}}\right)^{\frac{1}{n}}}
\end{gathered}
$$

In the formula, $E x_{i}^{0}$ is the expectation of the i-th factor weight cloud model, $E n_{i}^{0}$ is the entropy of the i-th factor weight cloud model, $\mathrm{He}_{i}^{0}$ is the hyper entropy of the i-th factor weight cloud model, and ij represents the $\mathrm{i}$-th row and j-column of the judgment matrix.

The fifth step was to improve "Method 1" by combining relevant parameters of the comment set cloud model. When the entropy of the weight cloud model of a factor was greater than the comment set of cloud model, the entropy of the weight cloud model of this factor was modified to the entropy of the comment set of cloud model, and the hyper entropy was modified to the hyper entropy of the comment set of cloud model.

\section{Degree of Membership Cloud Model}

Membership function is the core part of fuzzy comprehensive evaluation method, which is used to characterize the degree of membership of the evaluation factor belonging to the certain comment set. The commonly used methods included f-statistical method, expert experience method, binary comparison, and sorting method, etc. Because these methods expressed the membership relation of evaluation factors to the comment set as an accurate and unique value, there were problems such as strong subjectivity and insufficient expression of the one-to-many mapping relation between qualitative and quantitative.

Based on the principle of reverse cloud generator, this paper constructed the membership functions of each evaluation factor and each evaluation grade by organizing experts and scholars from local and related scientific research institutions and fully described

Table 2. Correspondence between average random consistency factor and order [32].

\begin{tabular}{|c|c|c|c|c|c|c|c|c|c|c|}
\hline Geometric order of matrix & 1 & 2 & 3 & 4 & 5 & 6 & 7 & 8 & 9 & 10 \\
\hline$R I$ & 0.00 & 0.00 & 0.58 & 0.90 & 1.12 & 1.24 & 1.32 & 1.41 & 1.45 & 1.49 \\
\hline
\end{tabular}


the one-to-many mapping relationship between each evaluation factor and evaluation grade. The calculation process is as follows:

(1) Organizing experts and scholars from local and related scientific research institutions to grade the evaluation of each factor level according to the comprehensive benefit evaluation set of water-saving irrigation in the irrigated areas;

(2) Calculating the expectation $\left(E x_{i}^{1}\right)$ of the membership cloud model, that is, the average value of cloud droplets in the cloud model:

$$
E x_{i}^{1}=\frac{1}{n} \cdot \sum_{a=1}^{n} x_{a}^{i}
$$

(3) Calculating the entropy $\left(E n_{i}{ }^{1}\right)$ of the membership cloud model:

$$
E n_{i}^{1}=\sqrt{\frac{\pi}{2}} \cdot \frac{1}{n} \cdot \sum_{n=1}^{n}\left|x_{a}^{i}-E x_{i}^{1}\right|
$$

(4) Calculating the hyper entropy $\left(H e_{i}^{1}\right)$ of the membership cloud model:

$$
H e_{i}^{1}=\sqrt{\frac{1}{n-1} \cdot\left|\sum_{a=1}^{n}\left(x_{a}^{i}-E x_{i}^{1}\right)^{2}-E n_{i}^{12}\right|}
$$

(5) Checking the validity of the evaluation value [27]. When $H e<E n / 3$, the cloud model is in a good state. When $H e>E n / 3$, the atomization state of the cloud model is more obvious, and it is necessary to feedback the results with the expert team in time. Experts from the expert group re-evaluate until the validity test is passed.

In the formula, $x_{a}{ }^{i}$ is the score of the $\mathrm{i}$-th factor by the a-th expert, $E x_{i}^{1}$ is the expectation of the i-th factor membership degree cloud model, $E n_{i}{ }^{1}$ is the entropy of the i-th factor membership cloud model, $\mathrm{He}_{i}{ }^{1}$ is the hyper entropy of the i-th factor membership cloud model.

\section{Method of Result Calculation}

In the calculation of cloud model comprehensive evaluation results, the result calculation methods can be roughly divided into two categories according to the different weight calculation methods.

One is the cloud model comprehensive benefit evaluation system with weight cloud model in the evaluation process $[26,29]$. Its calculation formula is as follows:

$$
X=Y \otimes Z
$$

Among them, $X$ is the result cloud model of comprehensive evaluation; $Y$ is the membership cloud model of each factor to the comment layer; $Z$ is the comprehensive weight cloud model of each factor to the comment layer.

The specific parameters in this formula are calculated by referring to the cloud model calculation rule [33].

The other is the comprehensive benefit evaluation system of the cloud model without establishing the weight cloud model $[27,30]$, which only considers the expectation of the weight cloud model and ignores the entropy and hyper entropy of the weight cloud model. The calculation formula is as follows:

$$
\begin{gathered}
E x=\sum_{i=1}^{n}\left(E x_{i}^{1} \cdot w_{i}\right) \\
E n=\sqrt{\sum_{i=1}^{n}\left(E n_{i}^{1} \cdot w_{i}\right)} \\
H e=\sum_{i=1}^{n}\left(H e_{i}^{1} \cdot w_{i}\right)
\end{gathered}
$$

In the formula, $E x$ is the expectation of the evaluation result cloud model, $E n$ is the entropy of the evaluated cloud model, $\mathrm{He}$ is the hyper entropy of the evaluated cloud model, $\left(E x_{i}^{1}\right)$ is the expectation of the i-th factor membership degree cloud model, $\left(E n_{i}{ }^{1}\right)$ is the entropy of the i-th factor membership degree cloud model, $\left(\mathrm{He}_{i}{ }^{1}\right)$ is the hyper entropy of the $\mathrm{i}$-th factor membership degree cloud model, $w_{i}$ is the weight of the i-th factor.

In this paper, the two methods were combined to carry out a comparative study.

In the analysis of comprehensive evaluation results of cloud model, the cosine method and expectation curve method were commonly used, but these two methods have disadvantages such as large dependence on the expected value and insufficient consideration of entropy and hyper entropy [31]. In this paper, the similarity calculation method of the normal cloud model with both shape and distance was adopted, and the effect of expectation, entropy and hyper entropy on the result analysis was fully considered.

Taking the similarity calculation of cloud model C11 $\left(\mathrm{Ex}_{1}, \mathrm{En}_{1}, \mathrm{He}_{1}\right)$ and cloud model $\mathrm{C} 22\left(\mathrm{Ex}_{2}, \mathrm{En}_{2}, \mathrm{He}_{2}\right)$ as examples, the specific calculation process is as follows.

The first step was to calculate the shape similarity of cloud model C11 and cloud model C22.The specific formula is as follows.

$$
\phi_{s} C 11, C 22=\frac{\min \left(\sqrt{E n_{1}^{2}+H e_{1}^{2}}, \sqrt{E n_{2}^{2}+H e_{2}^{2}}\right)}{\max \left(\sqrt{E n_{1}^{2}+H e_{1}^{2}}, \sqrt{E n_{2}^{2}+H e_{2}^{2}}\right)}
$$

The second step was to calculate the entropy ratio $(k, k>1)$ of cloud model $\mathrm{C} 11$ and cloud model C22, and calculate parameter $\left(\theta_{0}\right)$ by $k$. The specific formula is as follows. 


$$
\begin{gathered}
k=\frac{\max \left(E n_{1}, E n_{2}\right)}{\operatorname{mix}\left(E n_{1}, E n_{2}\right)} \\
\theta_{0}=1-\frac{2}{k+1}
\end{gathered}
$$

The third step was to compare the relevant data table of the fitting results [31]. According to the parameters $\mathrm{k}$ and $\theta_{0}$ obtained in the second step, we look up the table and get formula (18), then the relevant parameters $\mathrm{a}, \mathrm{b}$ and $\mathrm{c}$ in the distance similarity function got.

$$
\phi_{d}=a \cdot e^{-\left(\frac{\theta-b}{c}\right)^{2}}
$$

The fourth step was to calculate the distance $(\theta)$ of expectation between the two clouds.

$$
\theta=\frac{\left|E x_{1}-E x_{2}\right|}{3\left(E n_{1}-E n_{2}\right)}
$$

The fifth step was to calculate the similarity $\left(\phi_{d}\right)$ of the distance between the two clouds according to formula (18) and the obtained a, b, c and $\theta$.

The sixth step was to calculate the comprehensive similarity $(\phi)$ of the two clouds.

$$
\phi=\phi_{s} \cdot \phi_{d}
$$

\section{Results and Discussion}

Results

\section{Construction of Comment Set Cloud Model}

The comment set of the comprehensive benefit of water-saving irrigation was established to facilitate the quantitative evaluation of the comprehensive benefit of regional water-saving irrigation. This paper divided the comprehensive benefit of water-saving irrigation into four grades: excellent (grade I $=0.75-1$ ), good (grade $\mathrm{II}=0.5-0.75$ ), average (grade III $=0.25-0.5)$, and poor (grade IV $=0-0.25)$. According to formulas (1)-(3), the corresponding characteristic parameters of the cloud model of each grade were calculated respectively, and the parameters of the grades are:

Grade I $(0.875,0.1062,0.01)$, grade II $(0.625,0.1062,0.01)$, grade III $(0.375,0.1062,0.01)$, and grade IV $(0.125,0.1062,0.01)$.

The forward cloud generator was used to simulate the cloud model of comprehensive benefit evaluation of water-saving irrigation with MATLAB, as shown in Fig. 2.

\section{Construction of Factor Weight Cloud Model}

Experts and scholars from local and related scientific research institutions were organized to make pairwise comparison of various benefits and the importance of factors in the criterion layer and factor layer by using the scale criterion of factor weight cloud model in Table 1, and then a judgment matrix was established. According to formulas (4)-(7), the constructed judgment matrix was calculated, and the consistency test of the weight cloud model was conducted. After passing the

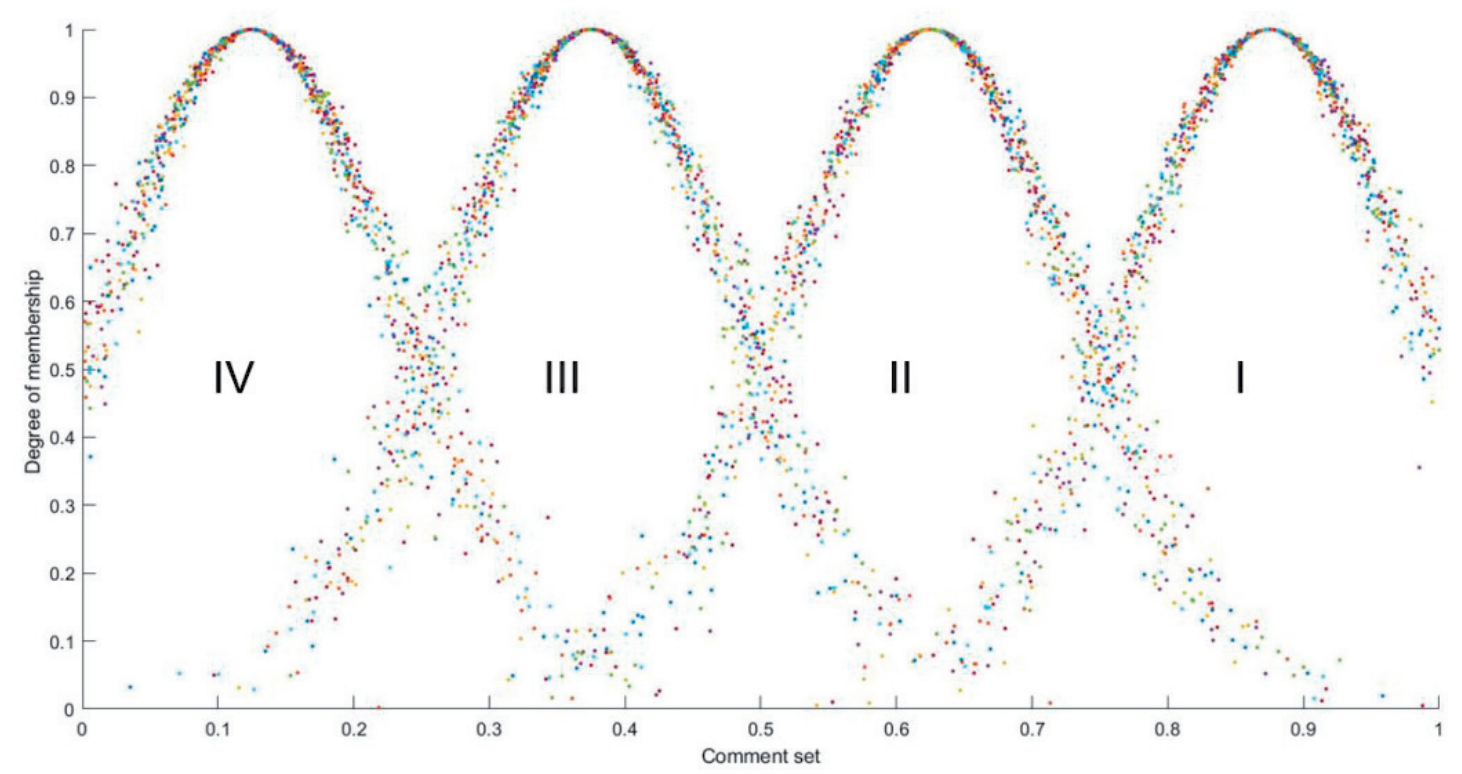

Fig. 2. Comment set of cloud model. 
Table 3. Parameters of weight cloud model of criteria layer.

\begin{tabular}{|c|c|c|c|}
\hline Criteria layer & Expect & Entropy & Hyper entropy \\
\hline $\mathrm{B}_{1}$ Economic benefit & 0.3656 & 0.3662 & 0.3627 \\
\hline $\mathrm{B}_{2}$ Ecological benefit & 0.3324 & 0.3380 & 0.3347 \\
\hline $\mathrm{B}_{3}$ Social benefit & 0.3020 & 0.2957 & 0.3026 \\
\hline
\end{tabular}

test, the parameters of the weight cloud model of the criteria layer (Table 3) and factor layer (Table 4) were obtained.

The parameters in Table 4 are modified according to relevant parameters of comment set cloud model. Since the entropy of the four factors $\mathrm{C}_{1}$ (The increase of gross agricultural product), $\mathrm{C}_{10}$ (The improvement of surface and groundwater quality), $\mathrm{C}_{12}$ (The improvement of rural life quality), and $\mathrm{C}_{13}$ (The benefit of disaster prevention and mitigation) is greater than the entropy of the comment set cloud model, the entropy of the weight cloud model of the four factors is revised to the entropy of the comment set cloud model, which is 0.1062 , and the hyper entropy of the four factors is revised to the hyper entropy of the comment set cloud model, which is 0.01 . Therefore, the randomness and ambiguity of each factor is fully considered while improving the accuracy of the evaluation results.

\section{Construction of Membership Cloud Model}

Experts and scholars from local and related scientific research institutions were organized to score each factor at the factor layer, referring to the comment set of comprehensive benefit evaluation of watersaving irrigation. According to the formulas (8)-(10), the relevant parameters were calculated, and finally, the validity of the calculation results was tested. If the test was passed, the membership cloud model of the factor layer could be obtained. Parameters of the membership cloud model of the factor layer are obtained in Table 5.

Among them, the changes of $\mathrm{C}_{2}$ (The change of agricultural production input) and $\mathrm{C}_{9}$ (The change

of groundwater level) were negative effects.

\section{Results of Evaluation}

Method 1, method 2 and method 3 (the improved algorithms in this paper) were respectively used to calculate the results of the comprehensive evaluation of the cloud model.

Parameters of the evaluation result cloud model were obtained in Table 6.

According to the evaluation results in Table 6, combining with formulas (15)-(20), the similarity calculation method of the normal cloud model with both shape and distance was used to calculate the similarity of each result and each grade in the comment set. The similarity of each result and each grade in the comment set was obtained in Table 7 .

It can be seen from Table 7 that the similarity of grade II is the highest and the comprehensive benefit of water-saving irrigation in Yahekou irrigated areas is good belonging to grade II according to the evaluation results obtained by the three methods.

Table 4. Parameters of weight cloud model of factor layer.

\begin{tabular}{|c|l|l|c|}
\hline Factor layer & Expect & Entropy & Hyper entropy \\
\hline $\mathrm{C}_{1}$ The increase of gross agricultural product & 0.3199 & 0.4528 & 0.4506 \\
\hline $\mathrm{C}_{2}$ The change of agricultural production input & 0.0457 & 0.0647 & 0.0644 \\
\hline $\mathrm{C}_{3}$ Carbon fixation and oxygen supply & 0.0147 & 0.0209 & 0.0208 \\
\hline $\mathrm{C}_{4}$ Air purification & 0.0147 & 0.0209 & 0.0208 \\
\hline $\mathrm{C}_{5}$ The prevention and control of soil secondary salinization & 0.0398 & 0.0574 & 0.0571 \\
\hline $\mathrm{C}_{6}$ The prevention and control of sediment deposition & 0.0244 & 0.0356 & 0.0355 \\
\hline $\mathrm{C}_{7}$ The storage of soil nutrients & 0.0627 & 0.0904 & 0.0900 \\
\hline $\mathrm{C}_{8}$ The increase of land area & 0.0398 & 0.0574 & 0.0571 \\
\hline $\mathrm{C}_{9}$ The change of groundwater level & 0.0147 & 0.0209 & 0.0208 \\
\hline $\mathrm{C}_{10}$ The improvement of surface and groundwater quality & 0.1217 & 0.1707 & 0.1698 \\
\hline $\mathrm{C}_{11}$ The scientific level of water management & 0.0189 & 0.0268 & 0.0268 \\
\hline $\mathrm{C}_{12}$ The improvement of rural life quality & 0.1321 & 0.1873 & 0.1873 \\
\hline $\mathrm{C}_{13}$ The benefit of disaster prevention and mitigation & 0.1321 & 0.1873 & 0.1873 \\
\hline $\mathrm{C}_{14}$ The enhancement of farmers' water saving awareness & 0.0189 & 0.0268 & 0.0268 \\
\hline
\end{tabular}


Table 5. Parameters of membership cloud model of factor layer.

\begin{tabular}{|c|c|c|c|}
\hline Factor layer & Expect & Entropy & Hyper entropy \\
\hline $\mathrm{C}_{1}$ The increase of gross agricultural product & 0.7909 & 0.1261 & 0.0263 \\
\hline $\mathrm{C}_{2}$ The change of agricultural production input & 0.5858 & 0.1076 & 0.0322 \\
\hline $\mathrm{C}_{3}$ Carbon fixation and oxygen supply & 0.2626 & 0.1154 & 0.0164 \\
\hline $\mathrm{C}_{4}$ Air purification & 0.2404 & 0.1087 & 0.0248 \\
\hline $\mathrm{C}_{5}$ The prevention and control of soil secondary salinization & 0.2624 & 0.1254 & 0.0302 \\
\hline $\mathrm{C}_{6}$ The prevention and control of sediment deposition & 0.5368 & 0.1243 & 0.0282 \\
\hline $\mathrm{C}_{7}$ The storage of soil nutrients & 0.7118 & 0.1198 & 0.0329 \\
\hline $\mathrm{C}_{8}$ The increase of land area & 0.7844 & 0.1362 & 0.0449 \\
\hline $\mathrm{C}_{9}$ The change of groundwater level & 0.2911 & 0.1368 & 0.0171 \\
\hline $\mathrm{C}_{10}$ The improvement of surface and groundwater quality & 0.4855 & 0.1259 & 0.0335 \\
\hline $\mathrm{C}_{11}$ The scientific level of water management & 0.7712 & 0.1041 & 0.0298 \\
\hline $\mathrm{C}_{12}$ The improvement of rural life quality & 0.6766 & 0.1049 & 0.0224 \\
\hline $\mathrm{C}_{13}$ The benefit of disaster prevention and mitigation & 0.8275 & 0.1118 & 0.0322 \\
\hline $\mathrm{C}_{14}$ The enhancement of farmers' water saving awareness & 0.7969 & 0.1092 & 0.0332 \\
\hline
\end{tabular}

Table 6. Parameters of the evaluation result cloud model.

\begin{tabular}{|c|c|c|c|}
\hline Method & Expect & Entropy & Hyper entropy \\
\hline Method One & 0.6161 & 0.3222 & 0.3186 \\
\hline Method Two & 0.6161 & 0.1198 & 0.0290 \\
\hline Method Three & 0.6161 & 0.1970 & 0.0919 \\
\hline
\end{tabular}

Table 7. The similarity of each result and each grade in the comment set.

\begin{tabular}{|c|c|c|c|c|}
\hline Method & Grade IV & Grade III & Grade II & Grade I \\
\hline Method One & 0.1138 & 0.2077 & 0.2333 & 0.2022 \\
\hline Method Two & 0.0247 & 0.2750 & 0.8840 & 0.2410 \\
\hline Method Three & 0.0679 & 0.3015 & 0.5012 & 0.2801 \\
\hline
\end{tabular}

\section{Discussion}

\section{Analysis of Index Benefit}

By comparing and analyzing the expectation of membership cloud model of factor layer, it is found that the last five places of expectation value are the change of agricultural production input (negative effect), the change of groundwater level (negative effect), air purification, the prevention and control of soil secondary salinization, carbon fixation and oxygen supply, which reflects the low recognition of experts on the development level of the five indicators of irrigation area.
One is the negative effect of the change of agricultural production input. Taking 2017 as an example, the input of summer corn and summer peanut in the Yahekou irrigated area increased by 1663.5 yuan per ha and 2745 yuan per ha, respectively, under irrigation. The reason is that the level of agricultural production technology in the research area is low, the primary water-saving measure is canal lining, the field water-saving measures are weak, and the intelligent degree of irrigation is low. Excessive irrigation means increase of water costs. The average labor cost of summer corn and summer peanut increased by 759 yuan per ha and 1207.5 yuan per ha, respectively, and the average water cost increased by 123 yuan per ha and 277.5 yuan per ha respectively. In addition, farmers in the irrigated areas have more extensive management of crops, and the use of chemical fertilizers and pesticides is scarce when the crops are not irrigated. After the crop irrigation is guaranteed, the farmers' demand for crop yield is stimulated, and more chemical fertilizers and pesticides are put in. Among them, the cost of pesticide of summer corn and summer peanut increased by 91.5 yuan per ha and 196.5 yuan per ha, respectively, and the cost of fertilizer increased by 690 yuan per ha and 1063.5 yuan per ha respectively. This is consistent with the related research [34, 35].

The second is the negative effect of the change of groundwater level. On the one hand, the amount of water diversion decreased significantly through the water-saving transformation of the irrigated areas. According to statistics, from 1971 to 1999, before the implementation of the project, the average volume of water diversion was 374.19 million cubic meters per year, and the average water consumption was 
6255 cubic meters per ha. From 2000 to 2017, after the implementation of the project, the average volume of water diversion was 107.49 million cubic meters per year, and the average water consumption was 2010 cubic meters per ha. Compared with the changes, the water diversion decreased by $71.27 \%$ per ha and the water consumption decreased by $67.87 \%$ per ha.

On the other hand, channel irrigation is the main measure of the Yahekou irrigated area, supplemented by good irrigation. In terms of water-saving reform, the main measure was canal lining, and there were few water-saving projects in the field. The comprehensive effect of these two factors directly led to the decrease of shallow groundwater levels in some areas of the irrigated areas. According to the field investigation in the irrigated areas, it was found that after the implementation of the water-saving renovation project in the irrigated areas in 2000, a large area of cracks appeared in some houses, and the pits and rivers dried up for years in the project areas, indicating that watersaving irrigation measures would bring certain negative environmental effects. This is consistent with the research conclusion of Du Jun [36] et al., that is: after the trunk canal lining in Hetao irrigated area, the burial depth of shallow groundwater in the irrigated areas continues to decline, which has a certain impact on the ecological environment.

The third is the carbon fixation and oxygen supply and air purification. Through communication with the experts and scholars involved in the assessment, it is concluded that water-saving irrigation experts and irrigated areas managers are generally unfamiliar with the concepts of carbon fixation and oxygen supply and air purification and have a weak sense of identity. No relevant literature has been hit by the search of topics and keywords "Water-saving irrigation" and "Carbon fixation and oxygen supply", as well as "Water-saving irrigation" and "Air purification" on Chinese and
English literature websites such as Zhiwang, Wanfang, Springer and Science-direct. Continue to search "Carbon fixation and oxygen supply" and "Air purification" on the relevant websites mentioned above. It is found that the relevant studies mostly appear in the fields related to ecology and environment such as soil and water conservation, indoor and outdoor air purification [37, 38]. This confirms the inference that experts in the field of water-saving irrigation generally do not have a strong sense of identity to the two concepts of "Carbon fixation and oxygen supply" and "Air purification".

The fourth is the prevention and control of soil secondary salinization. By analyzing the climatic and geological conditions of the irrigated areas, it is found that types of soil in the irrigated areas are mainly sandy soil, black soil, and old loess, which account for about $97 \%$ of the total area of the irrigated areas. The average annual rainfall in the irrigated areas is $802.7 \mathrm{~mm}$, the average evaporation on land is $558 \mathrm{~mm}$ per year, and the average annual temperature is $14.9^{\circ} \mathrm{C}$. The groundwater quality in the irrigated areas is good, most of which is freshwater with salinity less than $0.5 \mathrm{~g} / \mathrm{L}$. This is different from the natural conditions of the regions prone to secondary soil salinization pointed out in relevant literature [39]. It shows that the natural conditions of the irrigated areas have a certain inhibitory effect on the problem of secondary soil salinization. It is also the main reason for the low efficiency of water-saving irrigation in preventing and controlling secondary soil salinization in the Yahekou irrigated area.

\section{Analysis of Evaluation Results}

It can be seen from Table 6 that the ratio of hyper entropy to entropy reaches $98.88 \%$ and is close to 1 in the evaluation result obtained by method 1 . It shows that the cloud model obtained by method

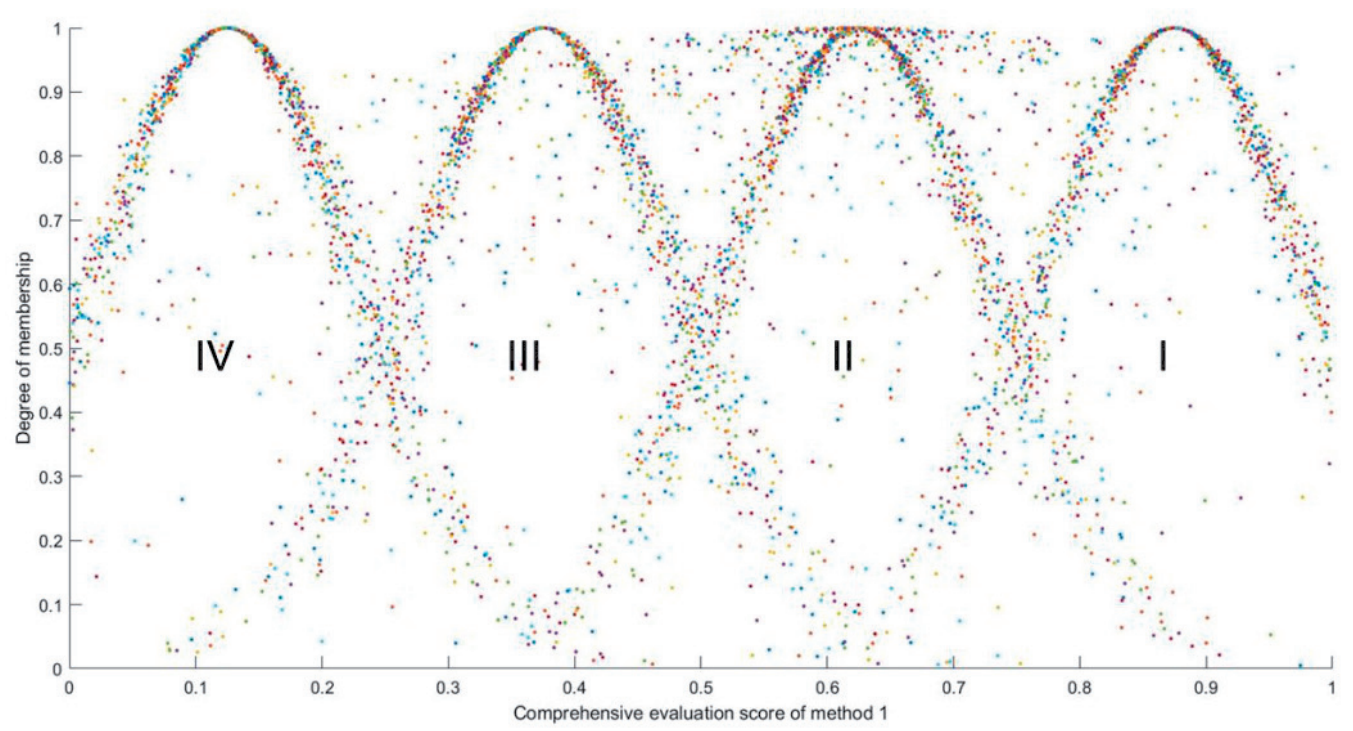

Fig. 3. Comprehensive evaluation results cloud model of method 1. 


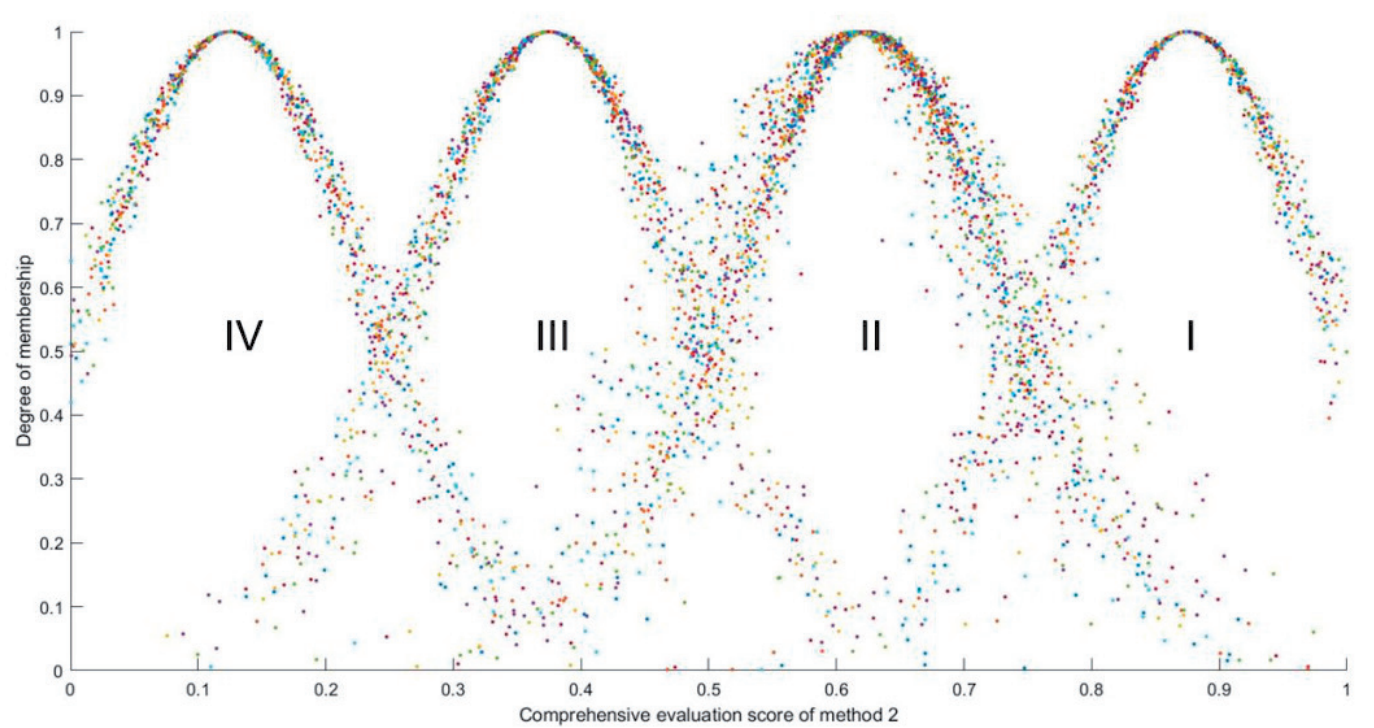

Fig. 4. Comprehensive evaluation results cloud model of method 2.

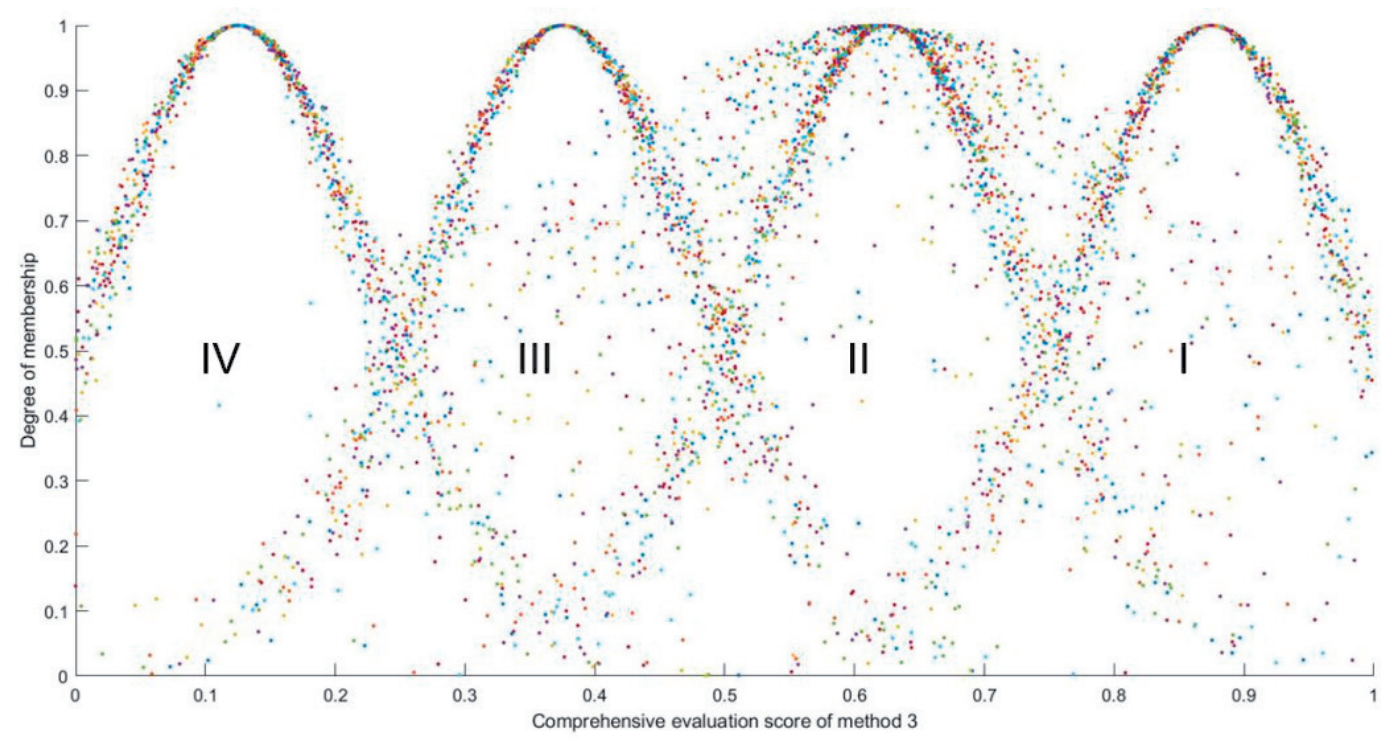

Fig. 5. Comprehensive evaluation results cloud model of method 3.

1 has strong atomization. The ratio of hyper entropy to entropy in method 2 and method 3 is $24.21 \%$ and $46.65 \%$, respectively. It is shown that the accuracy of the evaluation results is improved, and the randomness and fuzziness of each factor are fully considered by adjusting the parameters of the weighted cloud model.

The forward cloud generator was used to superpose the cloud model and the comment set cloud model of the comprehensive benefit evaluation results of watersaving irrigation obtained by the three methods, and the MATLAB software was used for simulation verification, as shown in Fig. 3, Fig. 4 and Fig. 5.

It can be seen from Fig. 3 that although the evaluation results of method 1 reflect randomness and fuzziness, the uncertainty is too strong. This is consistent with the dispersion degree of evaluation results obtained in similar studies $[26,29]$. The ratio of hyper entropy to the entropy of evaluation results in these studies is close to 1 , and the atomization degree of evaluation results in the cloud model is relatively severe. This also confirms the similarity calculation results in Table 7, that is, the similarity between the cloud model of evaluation result obtained by method 1 and the cloud model of level I, II and III of the comment set are relatively close, and the similarity between the evaluation result and level II is only 1.15 times of the similarity between the evaluation result and the adjacent level I, and 1.12 times of the similarity between the evaluation result and the adjacent level III, and the discrimination is small.

It can be seen from Fig. 4 that the evaluation results of method 2, which is obtained by ignoring the fuzziness and randomness of weights, have low 
atomization and high accuracy, which is consistent with the conclusions of relevant studies [27, 30]. It confirms the similarity calculation result in Table 7 , that is, the evaluation result of cloud model obtained in method 2 has a high similarity with the level II in the comment set cloud model while has a low similarity with other levels of the comment set of cloud models, and the similarity between the evaluation result and level II is 3.67 times of the similarity between the evaluation result and the adjacent level I, and 3.22 times of the similarity between the evaluation result and the adjacent level III.

It can be seen from Fig. 5 that the credibility of the evaluation results of method 3 is relatively high. Because on the basis of ensuring accuracy, it takes into account the ambiguity and randomness of the evaluation factors to the greatest extent. This confirms the similarity calculation result, that is, the evaluation results of cloud model obtained in method 3 has a high similarity with the level II in the comment set cloud model while has a low similarity with other grades of the comment set cloud models, and the similarity between the evaluation result and level II is 1.79 times of the similarity between the evaluation result and the adjacent level I, and 1.66 times of the similarity between the evaluation result and the adjacent level III.

\section{Conclusion}

This paper opens up a new way for the comprehensive benefit evaluation of water-saving irrigation in the irrigated areas, and also provides a new idea for the application and optimization of cloud model algorithm. The comprehensive benefit of water-saving irrigation in the Yahekou irrigated area is evaluated as grade II "good".

There are negative effects on the change of agricultural production input and the change of groundwater level. The benefits of air purification, the prevention and control of soil secondary salinization and carbon fixation and oxygen supply are less recognized. It reflects that the importance of enhancing the attention of experts and managers in the field of water-saving irrigation to ecological benefits and the importance of fully considering the precision, fuzziness and randomness, which is also the focus of future research.

\section{Acknowledgements}

The work was supported by the National Natural Science Foundation of China (51979108), the Zhongyuan Science and Technology Innovation Leadership Project (194200510008) and the Key Technologies R \& D and Promotion program of Henan (202102110128).

We thank the Water Conservancy Bureau of Nanyang, China for providing data for our study.

\section{Conflict of Interest}

The authors declare no conflict of interest.

\section{References}

1. PENG T., DENG H. Comprehensive evaluation on water resource carrying capacity in karst areas using cloud model with combination weighting method: a case study of Guiyang, southwest China. Environmental Science and Pollution Research, 2020.

2. GRAFTON R.Q., WILliAMS J., JIANG Q. Possible pathways and tensions in the food and water nexus. Earth's Future 5 (5), 449, 2017.

3. R.Q. GRAFTON J.W.C.J., PERRY F.M.C.R., B. UDALL S.A.W.Y., D. GARRICK R.G.A. The paradox of irrigation efficiency. science 361 (6404), 748, 2018.

4. ZHANG L., MA Q., ZHAO Y., WU X., YU W. Determining the influence of irrigation efficiency improvement on water use and consumption by conceptually considering hydrological pathways. Agricultural Water Management 213, 674, 2019.

5. BATCHELOR C., REDDY V.R., LINSTEAD C., DHAR M., ROY S., MAY R. Do water-saving technologies improve environmental flows? Journal of Hydrology 518, 140, 2014.

6. JU H., ZHANG Z., WEN Q., WANG J., ZHONG L., ZUO L. Spatial patterns of irrigation water withdrawals in China and implications for water saving. Chinese Geographical Science 27 (3), 362, 2017.

7. GOLABI M., HASILI M.A., BOROOMAND NASAB S. Study and evaluation of irrigation and drainage networks using analytic hierarchy process in Khuzestan province: A virtual water approach. Agricultural Water Management 241, 106305, 2020.

8. SUN H., WANG S., HAO X. An Improved Analytic Hierarchy Process Method for the evaluation of agricultural water management in irrigation districts of north China. Agricultural Water Management 179, 324, 2017.

9. FERERES E., VILLALOBOS F.J., ORGAZ F., MINGUEZ M.I., van HALSEMA G., PERRY C.J. Commentary: On the water footprint as an indicator of water use in food production. Irrigation Science 35 (2), 83, 2017.

10. XINCHUN C., MENGYANG W., XIANGPING G., YALIAN Z., YAN G., NAN W., WEIGUANG W. Assessing water scarcity in agricultural production system based on the generalized water resources and water footprint framework. Science of The Total Environment 609, 587, 2017.

11. HASHEMI M., SEPASKHAH A.R. Evaluation of artificial neural network and Penman-Monteith equation for the prediction of barley standard evapotranspiration in a semiarid region. Theoretical and Applied Climatology 139 (1-2), 275, 2020.

12. GUAN X., QIN H., MENG Y., WU Z. Comprehensive evaluation of water-use efficiency in China's Huai river basin using a cloud-compound fuzzy matter elemententropy combined model. Journal of Earth System Science 128 (7), 2019.

13. DING L., LIU Y. Application of comprehensive watersaving irrigation development level model based on FCE in a regional area. Engineering in Agriculture, Environment and Food 12 (1), 98, 2019. 
14. WANG M., SHAO G., MENG J., CHEN C., HUANG D. Variable fuzzy assessment of water use efficiency and benefits in irrigation district. Water Science and Engineering 8 (3), 205, 2015.

15. CHEN M., LUO Y., SHEN Y., HAN Z., CUI Y. Driving force analysis of irrigation water consumption using principal component regression analysis. Agricultural Water Management 234, 106089, 2020.

16. LIU S., CHEN N., HAO S., YANG L., CHANG Q. Evaluation of Ecological Service Value of Soil and Water Conservation in Danjiangkou Reservoir Area and Its Upper Reaches. Yellow River 40 (2), 88, 2018.

17. SUN L., LU W., YANG Q., MARTIN J.D., LI D. Ecological Compensation Estimation of Soil and Water Conservation Based on Cost-Benefit Analysis. Water Resources Management 27 (8), 2709, 2013.

18. ELLEUCH M.A., ANANE M., EUCHI J., FRIKHA A. Hybrid fuzzy multi-criteria decision making to solve the irrigation water allocation problem in the Tunisian case. Agricultural Systems 176, 102644, 2019.

19. ZHOU H., CHEN J., WANG F., LI X., GÉNARD M., KANG S. An integrated irrigation strategy for watersaving and quality-improving of cash crops: Theory and practice in China. Agricultural Water Management 241, 106331, 2020.

20. DING L., LIU Y. Application of comprehensive watersaving irrigation development level model based on FCE in a regional area. Engineering in Agriculture, Environment and Food 12 (1), 98, 2019.

21. BERBEL J., GUTIÉRREZ-MARTÍN C., EXPÓSITO A. Impacts of irrigation efficiency improvement on water use, water consumption and response to water price at field level. Agricultural Water Management 203, 423, 2018.

22. WU D., CUI Y., LUO Y. Irrigation efficiency and water-saving potential considering reuse of return flow. Agricultural Water Management 221, 519, 2019.

23. MAO K., ZHANG Q., XUE Y., WEEKS N. Toward a socio-political approach to water management: successes and limitations of IWRM programs in rural northwestern China. Frontiers of Earth Science 14 (2), 268, 2020.

24. XIAO J., LIU Y., TIAN L., CAO R. Application of entropy weight fuzzy matter element model in comprehensive benefit evaluation of water saving irrigation. Journal of Drainage \& Irrigation Machinery Engineering 34 (9), 809, 2016.

25. WANG G., XU C., LI D. Generic normal cloud model. Information Sciences 280, 1, 2014.

26. XU C., CHENG H., WANG Y., WAN R., LIU L., ZHANG R. Improved multi-level fuzzy evaluation model based on cloud theory for evaluation of soil salinization degree. Transactions of the Chinese Society of Agricultural Engineering 33 (27), 88, 2017.

27. XIA L., XIANG J., YANG J., WANG H., ZHANG C. Safety Evaluation of Radar Software System Based on Improved AHP and Cloud Model. Journal of Ordnance Equipment Engineering 40 (8), 145, 2019.
28. ZHANG Q., ZHANG Y., ZHONG M. A cloud model based approach for multi-hierarchy fuzzy comprehensive evaluation of reservoir-induced seismic risk. Shuili Xuebao/Journal of Hydraulic Engineering 45 (1), 87, 2014.

29. LI J., ZHANG Q., YAN F., ZHONG M. A cloud modelbased multi-level fuzzy comprehensive evaluation approach for financing credit of scientific \& technological small-medium enterprises. Journal of Difference Equations and Applications 23 (1-2), 443, 2016.

30. SUN Y., XIE J., SU K., LI Y. Civil and military integration decision evaluation model for military information system projects. Xitong Gongcheng Lilun Yu Shijian/system Engineering Theory \& Practice 38 (10), 2713, 2018.

31. WANG J., ZHU J., LIU X. An integrated similarity measure method for normal cloud model based on shape and distance. Xitong Gongcheng Lilun Yu Shijian/system Engineering Theory \& Practice 37 (3), 742, 2017.

32. JIANG G., WANG Z., SUO Y. Hierarchical analysis and fuzzy evaluation of comprehensive performance of typical water-saving irrigation techniques in Northwest China. Qinghua Daxue Xuebao/Journal of Tsinghua University 59 (12), 981, 2019.

33. SHEN J.C., SHU-XIN D.U., LUO Y., LUO J.Y., YANG Q., CHEN Z.F. Method and Application Research on Fuzzy Comprehensive Evaluation Based on Cloud Model. Fuzzy Systems \& Mathematics 26 (6), 115, 2012

34. ADEEL M., YANG Y.S., WANG Y.Y., SONG X.M., AHMAD M.A., ROGERS H.J. Uptake and transformation of steroid estrogens as emerging contaminants influence plant development. ENVIRONMENTAL POLLUTION 243 (B), 1487, 2018.

35. WANG H., ZHAO Y., ADEEL M., LIU C., WANG Y., LUO Q., WU H., SUN L. Characteristics and Health Risk Assessment of Potentially Toxic Metals in Urban Topsoil in Shenyang City, Northeast China. CLEAN - Soil, Air, Water 48 (1), 1900228, 2020.

36. DU J., YANG P.L., REN S.M., LI Y.K., DU J. Effects of canal-lining project on groundwater and ecological environment in Hetao Irrigation District of Inner Mongolia. Chinese Journal of Applied Ecology 22 (1), 144, 2011.

37. TANG J., HE M., LUO Q., ADEEL M., JIAO F. Heavy Metals in Agricultural Soils from a TypicalMining City in China: Spatial Distribution, SourceApportionment, and Health Risk Assessment. Polish Journal of Environmental Studies 29 (2), 1379, 2020.

38. ADEEL M., FAROOQ T., WHITE J.C., HAO Y., HE Z., RUI Y. Carbon-based nanomaterials suppress tobacco mosaic virus (TMV) infection and induce resistance in Nicotiana benthamiana. Journal of Hazardous Materials 404, 124167, 2021.

39. HAN D., ZHOU T., MA Y., SONG X. Water movement law through unsaturated zone in severe and mild salinealkali fields in arid region. Nongye Gongcheng Xuebao/ Transactions of the Chinese Society of Agricultural Engineering 34 (18), 152, 2018 